DOI

http://dx.doi.org/10.1590/2236-463320150907

Between the Local and Provincial: the Municipal Councils and the General Councils, São Paulo and Minas Gerais (1828-1834)

\section{Entre o local e o provincial: os Conselhos Gerais de Província e as Câmaras Municipais, São Paulo e Minas Gerais (1828-1834)}

Carlos Eduardo França de Oliveira

Doutor em História pela

Universidade de São Paulo (FFLCH /

USP - São Paulo-SP / Brasil)

e-mail: carlosoliveira@usp.br

\section{Resumo}

0 presente artigo procura analisar algumas das relações estabelecidas entre dois órgãos de importância fundamental para a conformação dos poderes locais ao longo do Primeiro Reinado e início da Regência, quais sejam, os Conselhos Gerais de Província e as Câmaras Municipais. Estas já atuavam como esfera privilegiada de poder local desde o período colonial, ao passo que os Conselhos Gerais, estipulados pela Carta de 1824, funcionaram como os principais canais de representação política em nível provincial até o Ato Adicional (1834). Serão privilegiados aqui os Conselhos Gerais e as Câmaras Municipais de São Paulo e Minas Gerais, escolha que não é fortuita. Juntamente com a Corte fluminense, Minas Gerais e São Paulo foram peças-chave na construção do eixo político que deu sustentação à ideia de uma monarquia constitucional com sede no Rio de Janeiro.

\section{Abstract}

This article aims to assay the relationship between the two main organs responsible for the local authorities construction throughout the First Reign and the beginning of the Regency: the General Councils and Municipal Councils. The Municipal Councils have served as privileged sphere of local government since the colonial period, while the General Councils, determined by the 1824 Constitution, functioned as the main channels of political representation at the provincial level to the Additional Act (1834). Priority will be given here the General Councils and Municipal Councils of São Paulo and Minas Gerais, that choice is not fortuitous. Along with Rio court, Minas Gerais and São Paulo were key pieces in the construction of the political axis that gave support to the idea of a constitutional monarchy based in Rio de Janeiro.

Palavras-chave

Conselhos Gerais, Câmaras Municipais, história do Império

Keywords

General Councils, Municipal Councils, Empire of Brazil 
A lei de 20 de outubro de 1823 criava o cargo de presidente e um conselho privativo - o Conselho da Presidência - para cada Província, excetuando a do Rio de Janeiro. Aos Conselhos da Presidência cabia propor e deliberar sobre questões relativas à infraestrutura da Província, fiscalizar os negócios provinciais e suspender determinados funcionários públicos. Cf. Lei de 20 de Outubro de 1823, que dá forma aos Governos das Províncias, criando para cada uma delas um Presidente e Conselho. In: Coleção das Leis do Império do Brasil de 1823. Rio de Janeiro: Imprensa Nacional, 1887. p.10-15. Por ser eletivo, o Conselho da Presidência consistia num braço do executivo provincial, firmando-se como importante contraponto à ação política do presidente de Província.
2

Cf. Art.71, Capitulo V - Dos Conselhos Gerais de Provincia e suas Atribuições, da Constituição Politica do Império do Brasil. In: BONAVIDES, Paulo; AMARAL, Roberto (orgs.). Textos políticos da História do Brasil. Brasília: Senado Federal, 2002. v.1.

3 Art.71, Capítulo V. Loc. Cit.

4 Art.71, Capitulo V. Loc. Cit.
Se a lei de 20 de outubro de $1823^{1}$ foi de importância crucial para a organização dos governos provinciais durante os primeiros anos do Império, outra instituição foi criada no ano seguinte, pela Carta de 1824, a fim de compor a estrutura político-administrativa das Províncias: os Conselhos Gerais. Dado que, além de provisória, a lei de 20 de outubro tinha como objetivo primordial contemplar a esfera executiva do poder provincial, lacunas permaneceram, após a dissolução da Constituinte, no que se referia à consolidação de canais efetivos de representação nas Províncias.

A Carta outorgada reconhecia e garantia a todos os cidadãos o direito de "intervir nos negócios de sua Província" que fossem "imediatamente relativos a seus interesses particulares". Tal direito seria assegurado pelas Câmaras Municipais e pelos Conselhos Gerais de Província, sendo esses últimos criados legalmente a partir daquele momento. Tais Conselhos deveriam ser instaurados em todas as Províncias, exceto naquela em que estivesse sediada a capital do Império. As mais populosas (Pará, Maranhão, Ceará, Pernambuco, Bahia, Minas Gerais, São Paulo e Rio Grande do Sul) contariam com vinte e um membros, ao passo que as demais possuiriam treze integrantes. Esses seriam eleitos na mesma ocasião e da mesma forma que os deputados e senadores, de modo que a permanência de cada membro no Conselho estaria condicionada à duração de cada legislatura, à semelhança do que ocorria com os Conselhos da Presidência. Os Conselhos Gerais teriam, ainda, um presidente e um secretário, ambos escolhidos por aclamação pelos seus membros. As sessões dar-se-iam uma vez por ano, com a duração de dois meses, podendo ser prorrogadas por mais um, caso a maioria dos conselheiros deliberasse nesse sentido. No dia da instalação dos Conselhos Gerais, prevista por lei para o $1^{\circ}$ de dezembro de cada ano, os Presidentes de Província fariam um discurso cujo objetivo era discorrer sobre o estado dos negócios públicos e instruir os conselheiros a respeito das providências necessárias a serem tomadas na administração provincial. ${ }^{2}$

Os Conselhos Gerais teriam como principal atribuição "propor, discutir e deliberar sobre os negócios mais interessantes de suas Províncias; formando projetos peculiares e acomodados às suas localidades e urgências", podendo inclusive receber projetos elaborados pelas Câmaras Municipais. Os Conselhos Gerais não estariam incumbidos de deliberar a respeito de propostas que recaíssem sobre a esfera dos "interesses gerais da nação", dos "ajustes de umas com outras Províncias", da "execução das leis" e sobre aquelas questões cuja iniciativa deveria partir exclusivamente da Câmara dos Deputados. ${ }^{3}$

Suas resoluções seriam remetidas "diretamente ao Poder Executivo, pelo intermédio do Presidente da Província". No caso da Assembleia Geral achar-se reunida por essa época, as resoluções ser-Ihes-iam enviadas e revertidas como "projetos de lei a obter a aprovação da assembleia por única discussão em cada câmara". Entretanto, nos períodos de recesso do Parlamento, o imperador poderia mandar executar "provisoriamente" as resoluções ou suspender seu juizo sobre a matéria. Tanto as resoluções provisoriamente executadas quanto aquelas temporariamente suspensas pelo imperador teriam como destino a Assembleia Geral após sua reabertura, a fim de serem discutidas e deliberadas. ${ }^{4}$

Incontornável, essa dupla subordinação - à Assembleia Geral e ao Executivo - balizava o alcance político do novo órgão: aos Conselhos Gerais não caberia legis/ar, mas sim propor matérias que, revertidas em projetos de lei, teriam que necessariamente passar pelo poder decisório dos 
5

DOLHNIKOFF, Miriam. O Pacto Imperial: origens do federalismo no Brasil. São Paulo: Globo, 2005.

6

LEME, Marisa Saenz. Dinâmicas centripetas e centrifugas na formação do Estado monárquico no Brasil: o papel do Conselho Geral da Província de São Paulo. Revista Brasileira de História, São Paulo, v.28, n.55, p.197-215, janeiro-junho de 2008; OLIVEIRA, Carlos Eduardo França de. Poder local e palavra impressa: São Paulo, 1824-1834. São Paulo: Annablume/Fapesp, 2011; SILVA, Ana Rosa Cloclet da. Identidades em construção. 0 processo de politização das identidades coletivas em Minas Gerais, de 1792 a 1831. Almanack Brasiliense, São Paulo, n.1, p.103-113, 2005; SILVA, Sandra Oenning da. Estado monárquico (des)centralizado: a dinâmica política em torno da formação dos conselhos provinciais de Santa Catarina (1824/1834). 2013. 173f. Dissertação (Mestrado em História Social). Centro de Filosofia e Ciências Humanas, Universidade Federal de Santa Catarina, Florianópolis, 2013; SLEMIAN, Andréa. Sob o império das leis: Constituição e unidade nacional na formação do Brasil (1822-1834). 2006. 338f. Tese (Doutorado em História Social). Faculdade de Filosofia, Letras e Ciências Humanas, Universidade de São Paulo, São Paulo, 2006.

7

Lei de 27 de Agosto de 1828 que dá regimento para os Conselhos Gerais de Província. In: Coleção das Leis do Império do Brasil de 1828. Rio de Janeiro: Tipografia Nacional, 1878. p.10-24.

8

"Do Presidente e Secretário", "Das sessões", "Das propostas", "Das discussões", "Das comissões", "Do modo de votar", "Das pessoas empregadas no serviço do Conselho" e "Da polícia". Cf. Lei de 27 de Agosto de 1828 que dá regimento para os Conselhos Gerais de Província. Loc. Cit.

9

Lei de 27 de Agosto de 1828 que dá regimento para os Conselhos Gerais de Província. Loc. Cit.

10

Decisão do ministério do Império de 29 de dezembro de 1829 - sobre a reunião do Conselho Geral da Província da Bahia. In: Coleção das decisões do Governo do Império do Brasil de 1829. Rio de Janeiro: Tipografia Nacional, 1877. p.232-233. Apesar da investida ministerial, foi somente a partir de 28 de fevereiro de 1830 que o Conselho Geral da Bahia passou a funcionar regularmente. Para o funcionamento do Conselho Geral na Bahia, ver CASTRO, Renato Berbert de. História do Conselho Geral da Província da Bahia, 1824-1834. Salvador: Assembleia Legislativa do Estado da Bahia, 1984.

11

O FAROL PAULISTANO. São Paulo, n.331, 17 de abril de 1830.

12

SLEMIAN, Andréa. Op. Cit., p.213. legisladores e do governo central. Em certo sentido, os Conselhos Gerais foram recebidos pelos próprios coetâneos como o prenúncio de um legislativo provincial. Aliás, vale sublinhar que os Conselhos Gerais estavam inscritos, na própria estrutura da Carta de 1824 , como braços do Legislativo, mesmo porque o capítulo que versava sobre tais órgãos foi incluso no Título IV (Do poder legislativo).

A carência de atribuição legislativa e a dependência da Assembleia Geral constituíram elementos preponderantes para que, durante a reforma da Carta de 1824, fossem requeridas a criação das Assembleias Legislativas Provinciais, ${ }^{5}$ embora estudos recentes venham apontando para o fato de que, mesmo com limitações, os Conselho Gerais se firmaram como importantes fóruns de discussão e prática política no âmbito da esfera pública provincial nos primeiros anos do Império. ${ }^{6}$ Ademais, a atuação dos Conselhos Gerais não pode ser medida apenas pela cristalização ou não de propostas, já que nem todas as suas atribuições estavam atreladas à ingerência do Legislativo e Executivo. Além de constituírem corpos eletivos direcionados para a criação de propostas referentes ao melhoramento dos negócios provinciais, os Conselhos Gerais resguardavam uma atribuição político-administrativa singular que não se atinha propriamente à esfera provincial, mas à municipal. Tratava-se do controle exercido pelos ConseIhos Gerais sobre as atividades desenvolvidas pelas Câmaras Municipais.

Essa vinculação ganhou concretude legal com a aprovação de um regimento especifico para os Conselhos Gerais, instrumento estipulado pela Carta de 1824 e assegurado pela lei de 27 de agosto de $1828 .^{7}$ Com cento e quinze artigos divididos em oito títulos ${ }^{8}$, o regimento para os ConseIhos Gerais formalizou seu funcionamento ordinário e ainda acrescentou algumas atribuições que apenas haviam sido esboçadas pelo Capitulo $5^{\circ}$ da Carta de 1824. Um dos principais aspectos contemplados pelo documento foi o da maneira como seriam trabalhadas as propostas elaboradas pelos membros dos Conselhos Gerais, bem como das representações emitidas pelas Câmaras Municipais. Estas seriam despachadas a uma comissão permanente encarregada de analisá-las e transformá-las em propostas. ${ }^{9}$

A instalação dos Conselhos Gerais não se processou de maneira uniforme pelas diversas Províncias do Império. No caso da Bahia foi necessária a intervenção do ministério do Império, em dezembro de 1829, para que se realizasse a reunião do Conselho Geral baiano daquele ano. Apesar de os conselheiros baianos atribuírem à falta de membros exigidos por lei o motivo para a não abertura do Conselho, o ministério ordenou sua imediata convocação para uma sessão preparatória, e que assim continuasse até completar o número de conselheiros determinado pela Carta de $1824 .{ }^{10}$ Situação análoga ocorreu no início de 1830, no Maranhão, que teve as atividades do seu Conselho Geral interrompidas temporariamente pelo não comparecimento de boa parte dos conselheiros. ${ }^{11}$ Ceará, Sergipe e Espírito Santo também tiveram como problema constante o não comparecimento dos membros eleitos, o que pode ser explicado por motivos diversos. Além da distância entre o local de residência de parte dos conselheiros e as capitais, e da ausência de gratificação (diferentemente do que ocorria com aqueles que compunham os ConseIhos da Presidência), houve inicialmente um relativo descrédito para com a natureza política dos Conselhos Gerais, que era eminentemente propositiva, e não legislativa. ${ }^{12}$ Havia, ainda, a exigência formal do reconhecimento dos diplomas dos membros do Conselho, que por vezes era morosa e acarretava no atraso do ingresso de alguns integrantes. 
Sobre a importância das Câmaras Municipais no processo de colonização portuguesa na América, ver BICALHO, Maria Fernanda. As Câmaras Municipais no Império Português: o exemplo do Rio de Janeiro. Revista Brasileira de História São Paulo, v.18, n.36, p.251-280, 1998; BOXER, Charles Ralph. 0 império marítimo português, 1415-1825. Tradução portuguesa de Anna Olga de Barros Barreto. São Paulo: Companhia das Letras, 2002, especialmente capítulo 12; Idem. Portuguese society in the tropics - the municipal councils of Goa, Macao, Bahia and Luanda, 1510 1800. Madison: University of Wiscosin Press, 1965; GARCIA, Rodolfo. Ensaio sobre a História Política e Administrativa do Brasil: 1500-1810. Rio de Janeiro/Brasília: José Olympio: MEC, 1975 RUSSEL-WOOD, Anthony John R. 0 poder local na América Portuguesa. Revista de História, São Paulo, v.55, n.109, p.25-79, 1977.

14

Ver, por exemplo, FAORO, Raymundo. Os Donos do Poder. Porto Alegre: Globo, 1958.

15

HOLANDA, Sergio Buarque de. A herança colonial - sua desagregação. In: (org.) História Geral da civilização brasileira. Tomo II: o Brasil Monárquico. Vol.1: o processo de emancipação. São Paulo: Difel, 1962. p.09-39; SOUZA, lara Lis Carvalho. A adesão das Câmaras e a figura do imperador. Revista Brasileira de História, São Paulo, v.18, n.36, p.367-394, 1998; GODOY, Mayr. A câmara municipal, uma estrutura política do poder legislativo na ordem local brasileira. São Paulo: Leud, 1978; BANDECCHI, Pedro Brasil. 0 município no Brasil e sua função política. Revista de História, São Paulo, n.90, p.495-530, abril-junho de 1972.

16

Lei de $1^{\circ}$ de outubro de 1828 - Dá nova forma as Câmaras Municipais, marca suas atribuições e o processo para a sua eleição, e dos Juízes de Paz. In: Coleção das Leis do Império do Brasil de 1828. Rio de Janeiro: Tipografia Nacional, 1878. p.74-88. Em verdade, outras iniciativas já haviam sendo tomadas pelo Governo e Parlamento com o intuito de minorar a força das municipalidades. A lei de 22 de setembro de 1828, além de abolir o tribunal da Mesa de Consciência e Ordens, extinguiu o do Desembargo do Paço, que era por onde se expediam assuntos da economia municipal. Cf. HOLANDA, Sergio Buarque de. Op. Cit., p.24.

17

A ideia era a de que, aos poucos, os assuntos municipais fossem retirados da alçada da Assembleia Geral e passados para a ingerência provincial. Este foi o argumento utilizado pelo senador pernambucano Bento Barroso Pereira quando convenceu os demais senadores da inutilidade de se criar, no Senado, uma comissão especial para as Câmaras Municipais, já que destas "tomavam conta os Conselhos Gerais". Cf. Anais do Senado do Império. Rio de Janeiro: Tipografia Nacional, 1914, sessão de 06 de maio de 1831. Tomo I, p.49-50.

18

OLIVEIRA, Carlos Eduardo França de. Op. Cit., capítulo 2.
Os Conselhos Gerais e as Câmaras Municipais: São Paulo e Minas Gerais, 1828-1834

Durante o período colonial, as Câmaras Municipais representaram um dos pilares da estrutura política, administrativa e jurídica da América portuguesa. ${ }^{13}$ Ainda que alguns historiadores tenham questionado ${ }^{14}$ sua preeminência no processo de colonização luso, é certo que atribuições como a aplicação da lei, a determinação de impostos, a imposição de normas, a administração dos bens municipais, a arrecadação das rendas locais e a nomeação de funcionários públicos fizeram das Câmaras fóruns de representações cujo papel foi inconteste no movimento de ocupação das terras americanas, bem como na estruturação dos poderes políticos locais.

Com o desencadeamento dos processos de Independência e construção de um Estado nacional independente, as Câmaras Municipais começaram a perder força, seja por conta do caráter mais centralizador que 0 governo do novo Império almejou implementar seja pelo fato de que se sobrepôs à municipalidade uma outra esfera de poder político, que por sinal foi fundamental para a viabilização de um projeto de estado monárquico unificado: o poder provincial. ${ }^{15}$

A recomposição do poder das Câmaras Municipais foi selada com promulgação da lei de $1^{\circ}$ de outubro de 1828 , cujo texto original foi concebido pelo Senado ${ }^{16}$. A partir dela as Câmaras Municipais foram definidas como "corporações meramente administrativas", deixando de exercer qualquer tipo de "jurisdição contenciosa". Em suma, municipalidades foram esvaziadas de sua capacidade legisladora e jurídica, ficando proibidas de definirem suas respectivas diretrizes administrativas e fiscais.

Um dos pontos marcantes da lei de $1^{\circ}$ de outubro de 1828 foi o de subordinar as Câmaras Municipais à esfera provincial e, mais especificamente, aos Conselhos Gerais. ${ }^{17}$ Em primeiro lugar, provimentos e posturas municipais deveriam passar pela aprovação daqueles órgãos - o que incluia eventuais emendas e alterações de conteúdo - para serem postos em vigência. No que tange à esfera financeira, marcou-se que as Câmaras Municipais seriam obrigadas, anualmente, a prestar suas contas aos Conselhos Gerais, de modo que esses provessem sobre elas como achasse conveniente. Na prática, os Conselhos Gerais ficaram responsáveis pela fiscalização das finanças tal como já vinham fazendo os Conselhos da Presidência. ${ }^{18}$

Os Conselhos Gerais funcionariam, ainda, como mediadores da prática político-administrativa das Câmaras e fiscalizadores do cumprimento da lei na esfera municipal. Obras públicas de "grande importância", no caso de envolverem particulares, deveriam ser remetidas aos Conselhos Gerais como propostas. 0 mesmo encaminhamento teriam as iniciativas das Câmaras cuja finalidade era aumentar suas rendas. Já as denúncias contra "infrações na Constituição", "prevaricações" ou "negligências" de quaisquer empregados públicos deveriam ser encaminhadas ao Presidente da Província, ${ }^{19}$ bem como aos Conselhos, que também apurariam as reclamações com relação aos maus tratos com escravos. Se por ventura os "cidadãos" se sentissem "agravados pelas deliberações, acórdãos e posturas das Câmaras", poderiam comunicar sua insatisfação aos Conselhos Gerais. ${ }^{20}$

Prescritas por lei, as relações entre as Câmaras Municipais e os Conselhos Gerais não constituíram letra morta, seja na sua instalação, seja no seu desdobrar cotidiano. As Câmaras Municipais costumavam consultar os Conselhos Gerais sobre a execução dos pontos da lei de $1^{\circ}$ de outubro de 1828 que atrelavam os dois órgãos. Em 1831, a Câmara Municipal de São 
Este ponto da lei foi elogiado pelo redator do jornal mineiro Pregoeiro Constitucional, pois ele estimularia os cidadãos a exigirem o cumprimento da lei e a se postarem contra os abusos de poder dos políticos locais. Cf. PREGOEIRO CONSTITUCIONAL. Pouso Alegre, n.25, 01 de dezembro de 1830.

20

Lei de $1^{\circ}$ de outubro de 1828 - Dá nova forma as Câmaras Municipais, marca suas atribuições, e 0 processo para a sua eleição, e dos Juizes de Paz. In: Op. Cit., p.79-86.

21

Cf. Coleção dos Diários do Conselho Geral da Província de Minas Gerais. Ouro Preto: Tipografia do Universal, 1831, sessão de 11 de janeiro de 1831. p.62.

22

A expectativa em torno do entrosamento entre os dois órgãos esteve presente na própria imprensa da época, a exemplo de nota inserida no jornal paulistano 0 Observador Constitucional, em novembro de 1829, às vésperas do início do segundo ano de funcionamento do Conselho Geral de São Paulo: "(..) Não menor número de projetos filantrópicas esperamos neste ano d'esta sabia reunião, que sendo a segunda trabalhará com mais acerto principalmente sobre os materiais que as Câmaras Municipais das diferentes vilas terão de lhe fornecer (...)", cf. 0 OBSERVADOR CONSTITUCIONAL. São Paulo, n.12 30 de novembro de 1829.

23

CARVALHO, Marcio Eulério Rios de. Afirmação de uma esfera pública de poder em Minas Gerais (1821-1851). 2003. 286f. Tese (Doutorado em História Social). Faculdade de Filosofia e Ciências Humanas, Universidade Federal de Minas Gerais, Belo Horizonte, 2003.

24

No caso da Câmara Municipal da cidade de São Paulo, aquelas posturas aprovadas pelo Conselho Geral de São Paulo chegaram a ser impressas e vendidas na Tipografia do Farol Paulistano separadamente dos periódicos ali publicados. Cf. O FAROL PAULISTANO. São Paulo, n.335, 27 de abril de 1830 .

25

Atas do Conselho Geral de Província de São Paulo, sessão de 20/12/1830. Apud. O FAROL PAULISTANO. São Paulo, n.433, 28 de dezembro de 1830.

26

Oficio do Secretário do Conselho Geral à Câmara. In: Registro Geral da Câmara Municipal de São Paulo, 1832. São Paulo: Publicação Oficial do Arquivo Municipal de São Paulo, 1936. v.XXII, p.32.

27

Nem os presidentes de Província, a partir de 1831, tinham o poder de intervir na aprovação das posturas municipais. Cf. Decisão do Ministério do Império de 17 de agosto de 1831 - declara que os Presidentes das Províncias nenhuma ingerência têm nas posturas das Câmaras Municipais, as quais somente são sujeitas à aprovação dos Conselhos Gerais. In: Coleção das decisões do governo de 1831. Rio de Janeiro: Tipografia Nacional, 1876. p.190.
José consultou o Conselho Geral de Minas sobre a possibilidade de empreenderem-se concertos e reparos em pontes e calçadas independentemente das formalidades presentes na lei de $1^{\circ}$ de outubro de $1828 .{ }^{21} 0$ vínculo dos Conselhos Gerais paulista e mineiro com as diversas municipalidades de cada Província deu-se de forma ininterrupta, valendo-se das distintas atribuições caucionadas quer pela Carta de 1824, quer pelos regimentos que regulavam ambos os órgãos. ${ }^{22} \mathrm{Em}$ Minas, a existência de uma comissão permanente nos Conselhos Gerais para o exame dos negócios municipais fortaleceu esse contato, que já vinha sendo cobrado desde sua criação, em 1824. ${ }^{23}$

A aprovação de posturas figurava como uma das principais atividades desenvolvidas pelos Conselhos Gerais com relação às Câmaras Municipais. Em linhas gerais, as posturas consistiam num conjunto de medidas formuladas e aprovadas pelos vereadores a respeito da condução da administração municipal. Pela lei de $1^{\circ}$ de outubro de 1828 elas se transformaram no principal instrumento legal das municipalidades, sendo inclusive publicadas por alguns periódicos da época, juntamente com as atas das Câmaras. ${ }^{24} \mathrm{Em}$ dezembro de 1830, o suplente Jose Antonio Pimenta Bueno sugeriu que as Câmaras Municipais comprassem uma tipografia para imprimirem seus trabalhos, com o objetivo de torná-los públicos e de facilitarem o expediente do Conselho Geral de São Paulo. ${ }^{25}$ Dois anos mais tarde, o mesmo Conselho recomendou a todas as Câmaras Municipais que compilassem suas posturas aprovadas pelo órgão, mandassem-nas imprimir e as vendessem pelo menor preço possivel, a fim de que essas chegassem "ao conhecimento dos habitantes dos seus municípios."26

0 trabalho de aprovação de posturas preenchia boa parte do expediente dos conselheiros de Minas e São Paulo, a começar por ser uma atribuição exclusiva dos Conselhos Gerais. ${ }^{27}$ Além da quantidade de municipalidades, requeria-se dos conselheiros um trabalho de análise, alteração, admissão ou supressão de artigo por artigo de cada postura. Mesmo com as constantes emendas feitas pelos conselheiros - o que levou o padre mineiro José Ribeiro Bhering a clamar por uma maior simplicidade na elaboração desses documentos pelos vereadores, e por medidas menos "opressivas ao povo" 28 -, a aprovação de posturas por parte dos Conselhos Gerais foi maciça e abrangente, ficando inclusive difícil precisar se houve um beneficiamento de algumas Câmaras Municipais em detrimento de outras. $^{29}$

Mesmo com essa expressiva aprovação de posturas, é crivel que algumas delas tenham sido cumpridas pelas administrações municipais antes mesmo de sua aprovação pelo Conselho Geral. Em 25 de outubro de 1831, a Assembleia Geral decretou que as Câmaras Municipais estavam proibidas de executar suas posturas antes da aprovação pelos Conselhos Gerais. Nas ocasiões em que tanto estes como a Assembleia Geral não estivessem em funcionamento, as posturas deveriam ser remetidas para os Presidentes de Província em reunião com o Conselho da Presidência, a fim de que esses mandassem executá-las provisoriamente. ${ }^{30}$ Extensivel à todas as Províncias do Império à exceção do Rio de Janeiro - daí a abrangência do decreto -, a execução das posturas antes de sua aprovação pode ter se dado, em parte, pelo curto período de funcionamento dos Conselhos Gerais, que talvez não conseguissem dar conta da análise de todo o material que lhes era enviado. Após o decreto, o Conselho de Minas Gerais passou a perguntar à presidência da Província a respeito de quais posturas haviam sido aprovadas provisoriamente durante 0 intervalo de funcionamento de suas sessões. ${ }^{31}$ 
O NOVO ARGOS. Ouro Preto, n.5, 10 de dezembro de 1829 , e n.6, 18 de dezembro de 1830

29

Cf. POSTURAS Municipais. São Paulo, 1830. Assembleia Legislativa do Estado de São Paulo. São Paulo, Brasil. Acervo Histórico da Assembleia Legislativa do Estado de São Paulo, Fundo Conselho Geral da Província, caixas 17, 18 e 19. Para Minas Gerais, ver Posturas da Câmara Municipal da imperial cidade de Ouro Preto confirmada pelo Conselho Geral da Província de Minas Gerais. Ouro Preto: Tipografia de Silva, 1830: Posturas da Câmara Municipal da leal cidade de Mariana confirmada pelo Conselho Geral da Província de Minas Gerais. Ouro Preto: Tipografia de Silva, 1829; Posturas policiais do termo da vila de Queluz. Ouro Preto: Tipografia de Silva, 1829

30

Decreto de 25 de outubro de 1831 - Proíbe a execução de posturas municipais antes de sua aprovação. In: Coleção das Leis do Império do Brasil de 1831. Rio de Janeiro, Tipografia Nacional, 1876. p.146-147.

31

Ver, por exemplo, Arquivo Público Mineiro. Belo Horizonte, Brasil. Seção Provincial, Presidência da Província, 1/52, cx.03, doc.13, ofício de 16/01/1832.

32

Ibidem, cx.04, doc.10, ofício de 05/12/1833.

33

De modo geral, a prestação de contas dos municípios era dividida em duas partes: de um lado havia a receita provinda de foros, multas, licenças e demais fontes de renda; de outro a despesa do município com ordenados de empregados, obras públicas, assinatura de periódicos, propinas e outros gastos. Ver Coleção dos Diários do Conselho Geral da Província de Minas Gerais. Op. Cit., sessão de 15/01/1831.

34

SLEMIAN, Andréa. Op. Cit., p.220-222.

35

Cf. Oficio do secretário do Conselho Geral à Câmara lido em sessão de 3 de fevereiro de 1830, sobre as contas. In: Registro Geral da Câmara Municipal de São Paulo, 1829-1830. São Paulo: Publicação Oficial do Arquivo Municipal de São Paulo, 1923. v. XX, p.273-274.

36

Atas do Conselho Geral de Província de São Paulo, sessão de 07/01/1830. Apud. O FAROL PAULISTANO. São Paulo, n.304, 06 de fevereiro de 1830.
Essa tentativa de agilizar a execução das posturas não impediu, entretanto, que as Câmaras Municipais agissem fora da nova legislação. Em dezembro de 1833, o Conselho Geral de Minas comunicou ao Presidente da Província sua "mágoa" em ver que a Câmara de Minas Novas exorbitara suas atribuições ao proibir a exportação de mantimentos para fora daquela vila, medida que só poderia ser tomada "por meio de posturas", nunca ao seu "bel-prazer".32

0 exame das finanças municipais consistia em outra atividade recursiva a ser desenvolvida pelos Conselhos Gerais. ${ }^{33}$ Províncias como Pernambuco e Ceará tiveram problemas com a prestação de contas pelas municipalidades, que se indispuseram com Conselhos Gerais, sendo provável que o mesmo tenha ocorrido com as demais Províncias do Império. ${ }^{34}$ No caso de São Paulo, o Conselho Geral exigiu, amiúde, que as Câmaras Municipais detalhassem mais minuciosamente suas contas, a fim de que essas fossem aprovadas com maior rigor e rapidez. Veja-se, por exemplo, o ofício enviado pela Secretaria do Conselho Geral de São Paulo à Câmara Municipal de São Paulo, em fevereiro de 1830, a respeito da prestação de contas pela Câmara paulistana: "Ilmos. Srs. - Tendo o Conselho Geral examinado as contas por W. Sas. Submetidas à sua revisão, e aprovação desde 6 de março até o fim de setembro do ano findo o mesmo notou $1 .^{\circ}$ - Que na 1.a conta tomada desde janeiro até 30 de abril faltam os rendimentos das cabeças de rezes das freguesias de Santo Amaro, e igualmente de MBoy, Itapecerica, e Juqueri; e o rendimento das entradas das aguardentes das freguesias de Juqueri, Conceição, Penha, São Miguel, e Ó. 2. - Que na 2.a tomada ao Procurador transato Antonio Justiniano de Souza só se mencionam os rendimentos das cabeças das freguesias de Itapecerica, e Ó, faltando os das outras. 3. - Que, quanto á conta dos rendimentos das entradas das aguardentes das deferentes freguesias, não vêm nela os de Juqueri, São Bernardo, Conceição, Penha, São Miguel, e Braz. $4 .{ }^{\circ}$ - Que, quanto á 2.a e 3.a. contas, tomadas ao atual Procurador desde o 1. ${ }^{\circ}$ de agosto até 30 de setembro do ano próximo passado, faltam na receita os rendimentos das cabeças de rezes de todas as freguesias, à exceção da de São Bernardo; os rendimentos das entradas de aguardentes das freguesias de Juqueri, Ó, Conceição, São Miguel, e Penha; por que o ali mencionado pertence ao ano da Câmara transata. Á vista pois das apontadas faltas resolveu o Conselho, que se pedisse a W. Sas. os necessários esclarecimentos, afim de poder ultimar o exame das referidas contas. Deus guarde a W. Sas. Paço do Conselho $1 .^{\circ}$ de fevereiro de 1830 - IImos. Srs. Da Câmara Municipal desta cidade de São Paulo - Manuel Joaquim de Amaral Gurgel".35

Neste sentido, assim como já acontecera anteriormente com 0 Conselho da Presidência, a análise financeira das Câmaras Municipais pelo Conselho Geral paulista não foi tarefa de execução simples, em virtude da falta de dados precisos sobre o estado das finanças e, sobretudo, da ausência de um critério de prestação de contas comum a todas as municipalidades. Ciente desse quadro, o suplente José da Costa Carvalho sugeriu, em janeiro de 1830, que a comissão voltada para as matérias referentes às Câmaras Municipais propusesse um modelo pelo qual as municipalidades formalizassem suas receitas e despesas, o que foi aprovado. ${ }^{36}$ Passados alguns meses, o Conselho Geral fez circular entre as Câmaras Municipais uma resolução que visava formalizar a prestação de contas pelos municipios. Não foi possivel estabelecer a sessão exata na qual foi aprovada essa resolução do Conselho Geral de São Paulo; é certo, todavia, que ela se deu 
Diz o ofício: "1. Que as Câmaras, na mesma ocasião da remessa das suas contas, enviem uma relação das rendas, que formam o fundo da sua receita, podendo vir como observação à margem, ou no fim do mesmo mapa, declarando se são arrematadas, ou administradas. $2 .^{\circ}$ que na mesma ocasião venha uma relação das suas dividas ativas e passivas. $3 .^{\circ}$ que de todas as obras novas, e concertos que se fizerem, excedendo a $10 \$ 000$, se proceda a avaliação por pessoas inteligentes da matéria, e se as ponha em praça a quem por menos fizer, e não havendo quem as arremate, que mandem fazê-las a jornal na forma do artigo 47 da lei do $1 .^{\circ}$ de outubro de 1828, fazendo-se menção da avaliação. $4 .{ }^{\circ}$ que as contas sejam remetidas imediatamente depois de tomadas as do $3 .^{\circ}$ trimestre de cada ano, a fim de ter 0 Conselho tempo de examiná-las. 5. ${ }^{\circ}$ finalmente, que as Câmaras remetam ao mesmo Conselho as contas dos anos transatos, que se não acharem examinadas, e sancionadas pelo governo, e que afirmem em seus ofícios com certidão do secretário o último ano, em que foram aprovadas. Deus guarde a Vossas Mercês. Paço do Conselho Geral de São Paulo, 8 de fevereiro de 1830 Senhores da Câmara Municipal desta Cidade de São Paulo - Manuel Joaquim do Amaral Gurgel, secretario". In: Registro Geral da Câmara Municipal de São Paulo, 1829-1830. Op. Cit., p.327-328.

38

0 número de membros da comissão, originalmente três, foi para cinco. Coleção dos Diários do Conselho Geral da Província de Minas Gerais. Op. Cit., sessão de 13/12/1830, p.31. Sobre irregularidades na prestação de contas das Câmaras Municipais, ver, por exemplo, Ibidem, sessão de 17/12/1831, p.43-46. Em outro sentido, o Conselho Geral tecia elogios para as Câmaras que demonstravam zelo para com seus gastos, cf. Ibidem, sessão de 17/12/1831, p.99-100.

39

Ibidem, sessão de 16/12/1831, p.79.

40

Regulamento para a Escrituração das Contas das Câmaras Municipais. Ouro Preto: Tipografia do Universal, 1832; Arquivo Público Mineiro. Belo Horizonte, Brasil. Seção Provincial, 3/2, cx.03, doc.03.

41

Coleção dos Diários do Conselho Geral da Província de Minas Gerais. Op. Cit., sessão de 03/02/1832, p.363-364; Arquivo Público Mineiro. Belo Horizonte, Brasil. Seção Provincial, Presidência da Província, 1/52, cx.03, doc.24, ofícios diversos. Para os embates entre a Câmara Municipal de Mariana e o Conselho Geral, ver ANDRADE, Pablo de Oliveira. A "legítima representante": Câmaras Municipais, oligarquias e a institucionalização do Império Liberal Brasileiro (Mariana, 1822-1836). 2012. 179f. Dissertação (Mestrado em História Social). Instituto de Ciências Humanas e Sociais, Universidade Federal de Ouro Preto, Mariana, 2012.

42

Decreto de 31 de outubro de 1831 - fixa regras para a contabilidade municipal e tomada das respectivas contas. In: Coleção das Leis do Império do Brasil de 1831. Op. Cit., parte primeira, p.175-176. entre janeiro e fevereiro de 1830. Com a resolução, fixaram-se diretrizes que se encontram transcritas num oficio enviado pelo Conselho Geral de São Paulo à Câmara Municipal da Capital paulista, lido em sessão de 16 de abril de $1830 .^{37}$

Em Minas Gerais, dada a abundância de vilas existentes na Província e as constantes irregularidades na prestação de contas pelos municípios, a análise destas sobrecarregou em demasia o Conselho, que teve de aumentar o número de membros da comissão originalmente destinados a esse trabalho ${ }^{38}$. 0 Conselho mineiro também agiu no sentido de padronizar tal procedimento, propondo um regulamento para a "escrituração das contas". 39 Alegando a necessidade de prescrever um método que servisse para regular a administração, arrecadação, distribuição e fiscalização das rendas municipais, o Conselho Geral de Minas aprovou, em janeiro de 1832, o Regulamento para a Escrituração das Contas das Câmaras Municipais, documento que aprofundava as ingerências do procurador municipal prescritas pela lei de $1^{\circ}$ de outubro de $1828 .{ }^{40}$ Os problemas, todavia, não deixariam de ocorrer. Após ser comunicada de uma resolução do Conselho Geral de Minas Gerais sobre a prestação de suas contas, a Câmara Municipal de Mariana negou-se a cumpri-la, qualificando-a de "injuriosa, injusta e degradante". Segundo ementa indicada pelo vereador marianense Gomes Pereira, o pedido de informações pelo Conselho era um ato de "acrimônia" em que se exigia o "servilismo" da Câmara. A comissão de representações do Conselho Geral repudiou severamente a conduta "intolerável" da Câmara de Mariana e, por acreditar que ela continha "injúrias e calúnias" contra os conselheiros gerais, decidiu encaminhar a questão à presidência da Província para que essa tomasse as providências cabiveis, principalmente com relação ao autor da ementa. ${ }^{41}$

No ano anterior à admissão do regulamento mineiro fora aprovado pelo Parlamento um decreto de proporções drásticas, cujo intuito era minorar tais dificuldades mediante a fixação de algumas regras quanto à organização das contas municipais, demonstrando que o problema era de grande amplitude. Com o decreto, as contas municipais tiveram seu ano financeiro regulado entre $01^{\circ}$ de outubro e o último dia de setembro do ano seguinte, devendo ser entregues nas respectivas capitais das Províncias em todo $01^{\circ}$ de dezembro, para daí sim serem remetidas aos Conselhos Gerais. Além disso, as Câmaras passaram a ter que prestar suas contas minuciosamente, discriminando arrecadações, gastos, dívidas e balanços para cada período abordado, sendo passiveis de multa caso não cumprissem com essas exigências. ${ }^{42}$

Ainda no que tange ao campo financeiro, é de se registrar o movimento contínuo das Câmaras Municipais na busca pelo aumento de suas rendas, atitude essa assegurada pelo artigo 77 da lei de $1^{\circ}$ de outubro de 1828. Em 1829, a Câmara Municipal de Itu solicitou ao Conselho Geral de São Paulo a permissão para a criação de uma loteria para o Hospital de Lázaros, a fim de que fornecesse as rendas necessárias para sua manutenção. Três anos mais tarde, os vereadores da vila paulista de Areias pediram permissão para que a Câmara Municipal pudesse vender o prédio da cadeia pública daquela vila para arrecadar recursos. ${ }^{43} \mathrm{Em}$ Minas Gerais, o Conselho Geral permitiu que a Câmara da vila de Pitangui passasse a administrar as rendas provenientes das pesagens daquela localidade da forma que achasse necessária, a fim de aumentar a arrecadação. ${ }^{44}$ Os Conselhos Gerais também elaboravam estratégias de gestão de finanças que aliassem os 
Assembleia Legislativa do Estado de São Paulo. São Paulo, Brasil. Fundo Conselho Geral de Província, CF29.004, caixa 01; CF32.074, caixa 15.

44

Coleção dos Diários do Conselho Geral da Província de Minas Gerais. Op. Cit., sessão de 19/01/1831, p.111. Vale notar que os Conselhos Gerais por vezes negavam tais pedidos, como ocorreu com a Câmara Municipal de Porto Alegre, cf. Anais do Parlamento Brasileiro, Câmara dos Deputados, sessão de 19/05/1830, p.176.

45

Coleção dos Diários do Conselho Geral da Província de Minas Gerais. Op. Cit., sessão de 17/12/1831, p.102.

46

Assembleia Legislativa do Estado de São Paulo. São Paulo, Brasil. Fundo Conselho Geral de Província. Ver, por exemplo, os documentos CP32.024, caixa 14; CP31.094, caixa 13; CP31.093, ESP 230; CP31.087, caixa 13; e CP31.073, caixa 13 , referentes a denúncias contra juízes de paz nas vilas de Jundiaí, Ubatuba, Taubaté, Sorocaba e São Paulo. Para Minas Gerais, ver a representação da Câmara de Paracatu sobre abusos de autoridade naquela vila, cf. Arquivo Público Mineiro, Belo Horizonte, Brasil. Seção Provincial, Presidência da Província, 1/52, cx.03, ofício de 05/01/1832; denúncia feita pela Câmara de Pitangui contra o juiz de fora daquela vila, cf. Coleção dos Diários do Conselho Geral da Província de Minas Gerais. Op. Cit., sessão de 10/01/1831, p.58; e a denúncia contra o juiz de paz do curato de S. Sebastião da Silva, cf. Ibidem, p.96.

47

0 indivíduo foi mantido preso sem formação de culpa e sentença condenatória. Cf. Centro de Documentação e Informação. Câmara dos Deputados, Brasília. Lata 47-A, maço 15, pasta 02, ofício de 25 de maio de 1830.

\section{8}

Atas do Conselho de Estado. Direção geral organização e intr. de José Honório Rodrigues. 13 vols. Brasília: Senado Federal, 1973-1978. 57 sessão, 21 de dezembro de 1830, p.92.

49

Dizia o artigo 58: "Darão parte anualmente, ou quando convier, ao presidente da Província e Conselho Geral das infrações da Constituição, e das prevaricações, ou negligencias de todos os empregados", Cf. Lei de $1^{\circ}$ de outubro de 1828 - Dá nova forma as Câmaras Municipais, marca suas atribuições, e o processo para a sua eleição, e dos Juizes de Paz. In: Op. Cit., p.82.

50

Participação feita pela Câmara ao Conselho Geral contra o vigário de São Bernardo. In: Registro Geral da Câmara Municipal de São Paulo, 1829-1830. 0p. Cit., p.343.

51

O FAROL PAULISTANO. São Paulo, n.322, 20 de março de 1830. interesses municipais com os de outras instituições. Foi o que fez o ConseIho Geral de Minas com a Câmara Municipal de São José del-Rei e a Santa Casa de Misericórdia daquela vila. Sugeriu-se a feitura de um contrato em que a Santa Casa ficaria obrigada a criar uma roda de expostos mediante o subsídio da Câmara joseense. ${ }^{45}$

Além de manejar as esferas administrativa e financeira das Câmaras Municipais, os Conselhos Gerais serviram, à maneira do Conselho da Presidência, como um espaço dedicado à apuração de denúncias contra crimes de abuso de poder, irregularidades na conduta da coisa pública e desrespeito à Constituição. Durante seu exercício, os Conselhos Gerais de São Paulo e Minas Gerais receberam denúncias contra ouvidores, juizes (de órfãos, ordinários e de paz), clérigos e militares. ${ }^{46}$ Mas diversamente do que ocorria no conselho privativo do presidente, onde as decisões eram tomadas mais agilmente, o Conselho Geral tinha que analisar as denúncias, redigi-las em forma de representações, submetê-las à aprovação dos demais conselheiros, enviá-las para a Assembleia Geral ou ao governo central, para ai sim ganharem concretude.

Isso não quer dizer, contudo, que resoluções desse tipo necessariamente malograssem. Em 1830, a Câmara Municipal de Ouro Preto denunciou ao Conselho Geral o juiz de paz daquela localidade, por ter prendido um indivíduo sem seguir as disposições prescritas pela lei. ${ }^{47} 0$ Conselho Geral de Minas analisou a denúncia contra Joaquim José da Silva Brandão, julgou-a procedente e a encaminhou à Câmara dos Deputados. Esta, por meio da comissão encarregada para examinar os trabalhos dos Conselhos Gerais, endossou a posição tomada pelo congênere mineiro, em vista dos dados oferecidos "provarem a manifesta violação da lei" pelo juiz de paz, que merecia a punição cabível. A denúncia foi parar no Conselho de Estado, que votou pela suspensão de Silva Brandão do cargo e inculcou que ele fosse "processado para ser punido como fosse de justiça, pelo escandaloso abuso de poder".48

Em meio às várias denúncias recebidas pelos Conselhos Gerais, sobretudo contra empregados públicos, foquemos nossa atenção num caso que, dada a sua amplitude, pode desnudar algumas das relações que mediavam essas esferas de poder. Em 21 de abril de 1830, invocando o artigo 58 da lei de $1^{\circ}$ de outubro de $1828^{49}$, a Câmara Municipal da capital paulista remeteu ao Conselho Geral de São Paulo uma denúncia contra o reverendo Higino Francisco Teixeira, na época vigário colado da freguesia de São Bernardo, por conta de seus "desleixos" e "abusos" cometidos na paróquia de sua responsabilidade. ${ }^{50} \mathrm{~A}$ acusação, também enviada ao conhecimento do executivo provincial, fora originalmente despachada ao presidente da Câmara Municipal de São Paulo pelo fiscal da freguesia de São Bernardo Manoel Rodrigues de Barros, a 12 de março de 1830, e publicada no próprio mês de março pelo jornal 0 Farol Paulistano. ${ }^{51}$ Após receber a denúncia da Câmara Municipal, o Conselho Geral de São Paulo trabalhou na sua apuração e, em 26 de janeiro de 1831, endossando a posição dos denunciantes, enviou uma representação ao monarca para que esse decidisse sobre o futuro do referido vigário. Ele foi acusado pelo Conselho de "prevaricação", o mesmo ocorrendo com o vigário geral da referida freguesia, que o havia defendido, segundo os conselheiros, por meio de um "patronato" parcial, que só corroborava com as denúncias contra o acusado. Como se tratava de um caso de interpenetração entre as esferas judicial e executiva, os conselheiros afirmaram que estavam "cumprindo o artigo $83 \S 4^{a}$ da 
Representação sobre o Pároco da Frega ${ }^{\text {. de }}$ S. Bernardo. Arquivo Público do Estado de São Paulo. São Paulo, Brasil. Registro de propostas, ofícios e representações, que subiram à presença de S. M. I. e da Assembleia Geral Legislativa, p.26.

53

Dizia o referido parágrafo: "Excetua-se a venda de pólvora, e de todos os gêneros susceptíveis de explosão, e fabrico de fogos de artifício, que pelo seu perigo, só se poderão vender, e fazer nos lugares marcados pelas Câmaras, e fora de povoado, para o que se fará conveniente postura que imponha condenação, aos que contravierem". Cf. Lei de $1^{\circ}$ de outubro de 1828. In: Op. Cit., parágrafo 11, art. 66, título II, p.84.

54

Representação sobre a inexequibilidade do $\S$ 11 do artigo 66 da lei de $1^{\circ}$ de outubro 1828 acerca da proibição da venda de pólvora dentro das Povoações. Arquivo Público do Estado de São Paulo. São Paulo, Brasil. Registro de propostas, ofícios e representações, que subiram à presença de S. M. I. e da Assembleia Geral Legislativa, p.16. Para a representação feita pela Câmara de São Carlos que foi enviada ao Conselho Geral de São Paulo, ver: Assembleia Legislativa do Estado de São Paulo. São Paulo, Brasil. Fundo Conselho Geral de Província, CP30.043, caixa 11.

55

Atas do Conselho Geral de São Paulo, sessão de 04/01/1830. Apud. O FAROL PAULISTANO. São Paulo, n.437, 11 de janeiro de 1831; Anais do Parlamento Brasileiro, Câmara dos Deputados, sessão de 15/05/1830.

56

Coleção dos Diários do Conselho Geral da Província de Minas Gerais. Op. Cit., sessão de 26/01/1832, p.321.
Constituição", que por seu turno exigia que os Conselhos Gerais enviassem à Assembleia Geral e ao Executivo questões dessa natureza. ${ }^{52}$

Não foi possivel esclarecer o desenlace do episódio, conquanto sua relevância esteja, todavia, menos na concretização da denúncia do que na teia de relações por ela estabelecida. Analisada por um viés mais amplo, intercomunicações como essa foram essenciais para a construção de uma prática política em nivel local, na medida em que proporcionaram o contato de diferentes vozes do espaço público paulista. Mais significativo ainda é o fato de que casos assim patenteiam como o início do processo de formação do Império gestou um jogo institucional que, permeado por brechas político-administrativas de um Estado ainda nascente, deixou espaço para que órgãos como os Conselhos Gerais atuassem de acordo com cada situação ou conjuntura política.

Nesses termos, ofuscada pela retórica do cumprimento da lei, subsistia a possibilidade do Conselho Geral gerenciar a política municipal de outra forma, no sentido de selecionar as matérias que seriam levadas adiante, bem como de transpor para as várias localidades da Província demandas relativas a uma determinada municipalidade. Em outras palavras, uma das formas de conduzir a política provincial podia se dar, até certo ponto, por meio da articulação das administrações municipais.

É exemplar neste ponto a resolução aprovada pelo Conselho Geral de São Paulo sobre a inexequibilidade do parágrafo 11 do artigo 66 da lei de $1^{1}$ de outubro $1828^{53}$, segundo o qual estava proibida a venda de pólvora ou de qualquer artefato explosivo em locais que não fossem despovoados e marcados pelas Câmaras Municipais. De acordo com o Conselho Geral, após refletir "maduramente sobre a representação da Câmara da Vila de S. Carlos, em que fez ver o quanto é inexequível o $\$ 11$ do artigo 66 da Lei de $1^{\circ}$ de outubro de 1828", o órgão constatou que o parágrafo mencionado era danoso para "toda a Província", já que a falta de acessibilidade à pólvora prejudicava a "caça" de animais e o "comércio" entre os habitantes, criando uma situação propícia para a "violação da lei".54 Assim, tomando como ponto de partida a realidade de uma municipalidade específica, 0 Conselho Geral alargou-a para o restante da Província, adequando-a num formato de política pública em nível provincial. Via de duas mãos, esse processo também servia, ao menos em tese, para que as Câmaras pleiteassem iniciativas mais amplas, que saissem do âmbito municipal e pudessem de algum modo atenuar as limitações políticas impostas pela lei de $1^{\circ} \mathrm{de}$ outubro de 1828. A representação foi recusada pela Câmara dos Deputados em junho de 1830, após anuir o parecer da comissão dos Conselhos Gerais, formada pelo deputado paulista José Correa Pacheco e Silva e pelos mineiros Aureliano de Souza Coutinho e Antonio Maria de Moura. 0 argumento da comissão foi de que não havia necessidade e nem era conveniente alterar esta parte da lei de $1{ }^{\circ}$ de outubro de $1828 .{ }^{55}$ Outro artifício do qual as Câmaras Municipais se serviam para inserir seus interesses no âmbito dos Conselhos Gerais era o de encaminhar representações que poderiam ser convertidas em propostas pelos conselheiros. Em 1832, "atendendo às representações" das Câmaras de Queluz, São João del-Rei e Campanha, o Conselho Geral mineiro aprovou a criação de cadeiras de retórica, filosofia e gramática para aquelas localidades. ${ }^{56}$

Convergente em alguns pontos, a relação entre Conselhos Gerais e Câmaras Municipais foi não poucas vezes conflituosa, e os embates iam além do âmbito fiscal, como já visto acima. Às vésperas do 7 de abril, a 
Ibidem, sessão de 11/02/1831, p.223. Situação semelhante ocorreu envolvendo a Câmara de Mariana, cf. ofício de 05/06/1830, publicado pelo jornal mineiro ESTRELA MARIANENSE. Mariana, n.22, 02 de outubro de 1830.

58

Ofício do Exmo. presidente da Província à Câmara. In: Registro Geral da Câmara Municipal de São Paulo, 1830-1831. São Paulo: Publicação Oficial do Arquivo Municipal de São Paulo, 1936 v.XXI, p.91-92.

59

CATELLI JR., Roberto. Poder local: consolidação e revolta. Sorocaba 1823-1842. 1993. 169f. Dissertação (Mestrado em História Social). Faculdade de Filosofia, Letras e Ciências Humanas, Universidade de São Paulo, São Paulo, 1993.

60

FEIJÓ, Diogo Antônio. Guia das câmaras municipais do Brasil no desempenho de seus deveres por um deputado amigo da instituição. Rio de Janeiro: Typografia D'Astréa, 1830.

61

Veja-se, por exemplo, a representação enviada pela Câmara da vila de Itapetininga ao Conselho da Presidência de São Paulo, em outubro de 1829, a respeito da concessão de terrenos devolutos. Cf. Atas do Conselho da Presidência da Província de São Paulo. In: Documentos Interessantes para a história e costumes de São Paulo. São Paulo: Departamento do Arquivo do Estado, 1961. v.86, sessão de 21 de outubro de 1829, p.258; ou 0 ofício encaminhado pela vila de Itu à Câmara dos Deputados pedindo a suspensão do imposto do selo de testamentos relativos aos legados feitos às casas de caridade daquela municipalidade, cf. Anais do Parlamento Brasileiro, Câmara dos Deputados, sessão de 13/05/1830, p.127. Para o caso mineiro, ver: Ibidem, sessão de 03/08/1833, p.144; Centro de Documentação e Informação, Câmara dos Deputados, lata 45, maço 8, pasta, ofício de 23/04/1830. Para outras Províncias, ver Anais do Parlamento Brasileiro, Câmara dos Deputados, sessão de 05/05/1830 (Bahia); sessão de 17/07/1830 (Espírito Santo), p.450; Anais do Senado do Império, sessão de 30 de junho de 1830 (Ceará).

62

Ver, por exemplo, um caso envolvendo a Câmara Municipal de Mecejena, que teve uma postura sua negada pelo Conselho Geral do Ceará. Cf. Anais do Parlamento Brasileiro, Câmara dos Deputados, sessão de 30/08/1830, p.450. No ano seguinte foi a vez da Câmara Municipal de Olinda criticar a atuação do Conselho Geral de Pernambuco, cf. Ibidem, sessão de 25/10/1831. Outras Câmaras, como a mineira de Queluz, encaminhavam posturas à Câmara dos Deputados para que essa tomasse alguma providência, mesmo sem ter sido negado pelo Conselho Geral, cf. Ibidem, sessão de 19/05/1832, p.176.

63

Anais do Senado do Império, sessão de 02 de junho de 1823.
Câmara da vila do Príncipe optou por não acatar a recomendação do Conselho Geral de Minas Gerais para que um vereador daquela localidade fosse readmitido após ter sido afastado do cargo pelos demais vereadores, por suposta conduta desordeira. Uma vez que, segundo a lei de $1^{\circ}$ de outubro de 1828, caberia aos Conselhos Gerais oferecer seu juízo sobre essas questões, o congênere mineiro julgou a atitude da Câmara "pouco decorosa à dignidade do Conselho" e que ela deveria ter "obedecido logo" o encaminhamento sugerido. Porém, como o vereador expulso não reclamou sua reincorporação, o Conselho admitiu que nestas circunstâncias "nada tinha a deliberar". ${ }^{57}$ Em março de 1831, o então Presidente de São Paulo Aureliano de Sousa Coutinho fez circular um ofício no qual censurava a negligência das Câmaras Municipais com relação à conservação das estradas da Província, notando que essas não cumpriram as "enérgicas recomendações" feitas pelo governo provincial nesse sentido. A existência de "Posturas" e de um "Regimento" próprio comporia um arcabouço legal que, segundo Sousa Coutinho, seria suficiente para que as Câmaras tomassem medidas sobre esse "objeto da maior importância". 58

Disciplinar as Câmaras Municipais constituiu, aliás, preocupação constante entre os legisladores dos primeiros anos do Império, que viram na minimização do poder municipal uma forma de coibir os excessos dos grupos locais, os quais se chocavam com o projeto de Estado liberal acalentado por boa parte dos membros da Câmara dos Deputados das primeiras legislaturas. ${ }^{59} \mathrm{Em}$ 1830, Diogo Antonio Feijó publicou seu Guia das câmaras municipais do Brasil no desempenho de seus deveres por um deputado amigo da instituição, uma espécie de manual pedagógico destinado à instrução dos membros da administração municipal, definindo conceitos - o que era uma "postura", por exemplo - e explicando como proceder em cada atividade relativa às Câmaras Municipais. ${ }^{60}$ Para figuras como Feijó, os vereadores eram considerados "políticos de aldeia", homens cuja projeção política não avançava para além da política local.

Outro ponto que permite matizar a força da lei de 1828 é o de que, nos primeiros anos do Império, as Câmaras Municipais continuaram a se portar, em alguns pontos, como anteriormente. Representações remetidas diretamente ao Rio de Janeiro ou ao Conselho da Presidência persistiram mesmo após a lei de $1^{\circ}$ de outubro, sendo algumas delas, aliás, colidentes com as decisões tomadas pelos Conselhos Gerais. ${ }^{61}$ Alguns municípios acudiam à Câmara dos Deputados ou ao Senado após reprovação de determinada postura pelos Conselhos Gerais, objetando as resoluções tomadas pelos mesmos. ${ }^{62}$ Em junho de 1832, a Câmara Municipal de Baependy comunicou ao Senado seu desagrado com relação a uma proposta do Conselho Geral mineiro sobre a criação de mais duas vilas a partir do território daquele município. ${ }^{63}$ Dois anos depois os vereadores de São João del-Rei enviaram um despacho à Câmara dos Deputados contestando uma resolução tomada pelo mesmo Conselho Geral sobre o imposto de 100rs cobrado a cada alqueire de terra. ${ }^{64}$ No caso da Câmara dos Deputados, havia uma comissão específica para tratar de representações provindas das municipalidades. De modo geral, as demandas municipais eram remetidas aos Presidentes de Províncias ou redistribuídas entre as demais comissões da Casa conforme o teor da matéria. ${ }^{65}$

0 envio de representações ao Legislativo e Executivo por parte das Câmaras Municipais não era bem visto por aqueles que queriam as municipalidades subordinadas ao poder provincial, sobretudo quando a pauta 
Anais do Parlamento Brasileiro, Câmara dos Deputados, sessão de 11/06/1834.

65

Ver, a título de exemplo, Ibidem, sessão de 08/08/1833, p.153.

66

Em julho de 1834, a freguesia mineira de Camanducaia enviou uma representação à

Câmara dos Deputados solicitando que essa a elevasse à condição de vila. Cf. Ibidem, sessão de 09/07/1834.

67

Ibidem, sessão de 09/07/1829, p.87.

68

0 UNIVERSAL. Ouro Preto, n.710, 13 de fevereiro de 1832.
Recebido para publicação em 07 de janeiro de 2014 Aprovado em 09 de junho de 2014 em questão era notadamente de interesse local, como no caso da criação de vilas. ${ }^{66}$ Numa discussão envolvendo o ofício enviado por um povoado da Bahia pedindo para que a Câmara dos Deputados a elevasse à vila, Bernardo Pereira de Vasconcelos apresentou o parecer o qual assinalava que "objetos de semelhante natureza não fossem remetidos à Assembleia sem que primeiro fossem examinados pelos conselhos". Afinal, ponderou o deputado mineiro, "o que tem a Assembleia com os objetos peculiares das Províncias?". Dever-se-ia, portanto, "recomendar ao governo que objetos particulares das Províncias fossem remetidos aos conselhos gerais".67 Anos depois, o periódico ouro-pretano 0 Universal sugeriu que as Câmaras Municipais encaminhassem suas representações aos Conselhos Gerais e à presidência da Província, e não ao Executivo, com o intuito de fortalecer as instituições locais e evitar desconfiança sobre elas. ${ }^{68}$

\section{Considerações Finais}

Pouco estudado pela bibliografia sobre o Primeiro Reinado e início da Regência, o controle da administração municipal pelos Conselhos Gerais foi tão importante quanto a proposição de medidas atinentes aos negócios provinciais, a começar pelo tempo e empenho despendidos nessa atividade que, por ser menos grandiloquente, passou despercebida pela maioria dos que se debruçaram sobre o funcionamento desse órgão. Em verdade, tratava-se de gerir unidades administrativas que compunham, no limite, o alicerce político-administrativo de cada Província, uma vez que, se a redução de poderes pela lei de $1^{\circ}$ de outubro de 1828 esvaziou a estrutura municipal, não o fez a ponto de negá-la; houve sim, paralelamente ao enfraquecimento da esfera municipal, uma transposição de ingerências para os Conselhos Gerais, que passaram a desempenhar parte das atribuições anteriormente detidas pelas municipalidades, na qualidade de órgãos subordinadores das Câmaras Municipais.

É conveniente, portanto, não confundir a diminuição da autonomia das municipalidades com a extinção do poder municipal em si, pois esse não se dissipou por inteiro. Mesmo porque a relação entre as Câmaras Municipais - órgãos portadores de uma cultura política que vinha sendo gestada desde o período colonial - e o Conselho Geral, instituição que estabelecia, dentro de uma perspectiva de regime representativo, uma nova relação de forças entre o local e o provincial, entrou repetidas vezes em rota de colisão, o que acena para um quadro nuançado, e não de simples sujeição, em que atuavam diferentes agentes da política.

A relação entre Câmaras Municipais e Conselhos Gerais não deve ser compreendida, entretanto, como realidade isolada. Do contato entre ambos os órgãos emergiram medidas voltadas para a padronização de atividades concernentes ao poder público, tais como a elaboração de representações e posturas municipais, a prestação de contas e o encaminhamento de processos judiciais. Tais medidas foram acompanhadas de esforços que procuraram regular as diferentes esferas da sociedade, como a militar e os sistemas educacional e de medidas. Os Conselhos e as Câmaras trabaIharam, portanto, no sentido de estabelecer um movimento contínuo de normatização e aperfeiçoamento da estrutura política provincial e local, que, num âmbito maior, conjugou-se ao gradativo - e muitas vezes errático - processo de institucionalização da máquina administrativa que deu tangibilidade ao Estado nacional brasileiro. 